\title{
IDENTIDADE, REFERENCIAÇÃO E TEXTO DIGITAL: UMA ANÁLISE LINGUÍSTICO-DISCURSIVA
}

\author{
IDENTITY, REFERENCE AND DIGITAL TEXT: A LANGUAGE-DISCURSIVE \\ ANALYSIS
}

Marize Barros Rocha Aranha ${ }^{1}$, Evaldo Carlos de Oliveira Cardoso ${ }^{2}$

\begin{abstract}
RESUMO: Ao articularmos os pressupostos teóricos da referenciação à questão da identidade e texto digital, mostraremos que essa tríplice relação é possível numa perspectiva de análise linguística e discursiva. Para tanto, fazemos uma breve abordagem sobre a trajetória evolutiva da Linguística Textual, com foco na referenciação, processo fundamental para a construção do sentido do texto; discutimos acerca da identidade do sujeito, a partir dos processos referenciais, enfatizando a construção dos objetos de discurso; também discorremos sobre o texto digital e suas características, centrando-nos na rede social Facebook como espaço de escrita do texto digital. O aporte teórico é constituído pelos seguintes autores: Araújo e Leffa (2016), Antunes (2010 e 2017), Bakhtin (2000), Barton e Lee (2015), Cavalcante (2012 e 2013), Charaudeau (2012), Hall (1999), Koch (2017), Martins (2016), Mondada e Dubois (2016), Roncarati (2010), Shepherd e Saliés (2013), e Silva (2007).
\end{abstract}

Palavras-chave: Identidade; Referenciação; Texto digital; Discurso.

ABSTRACT: By articulating the theoretical presuppositions of reference to the question of identity and digital text we will show that this triple relationship is possible from a perspective of linguistic and discursive analysis. In order to do so we make a brief overview of the evolutionary trajectory of Textual Linguistics focusing on reference, a fundamental process for the construction of the meaning of the text; we discuss the identity of the subject, starting from the referential processes, highlighting the construction of the objects of discourse; we also talk about digital text and its characteristics, focusing on the Facebook social network as a space for writing digital text. The theoretical framework consists of the following authors: Araújo and Leffa (2016), Antunes (2010 \& 2017), Bakhtin (2000), Barton and Lee (2015), Cavalcante (2012 \& 2013), Charaudeau (2012), Hall (1999), Koch (2017), Martins (2016), Mondada and Dubois (2016), Roncarati (2010), Shepherd and Saliés (2013), and Silva (2007).

Keywords: Identity; Reference; Digital text; Discourse.

\section{Introdução}

O processo evolutivo por que passou a Linguística Textual, notadamente, a transição de uma postura de análise centrada no cotexto (endofórica) para outra postura que leva em

\footnotetext{
${ }^{1}$ Mestra em Educação (UFMA), doutora em Linguística e Língua Portuguesa na UNESP/SP e Professora do Departamento de Letras da UFMA. Professora do Programa de Pós-Graduação em Letras - PGLetras e do Programa de Pós-Graduação em Gestão de Ensino da Educação Básica - PPGEEB da UFMA.

${ }^{2}$ Mestrando do Programa de Pós-Graduação em Letras - PPG Letras.
} 
conta o contexto e as interações sociais (exofórica), culminou com o surgimento de uma nova forma de estudar o texto e de desvendar seus segredos: a referenciação.

Neste trabalho, buscamos investigar, pelo viés linguístico-discursivo, a relação entre referenciação e construção de identidade no texto digital, analisando comentários extraídos da rede social Facebook.

Para atingir este fim, a primeira parte de nosso percurso começa com uma abordagem geral sobre a evolução da Linguística Textual, que culmina com a apresentação dos fundamentos teóricos da referenciação, cujos processos são essenciais para a construção do sentido do texto. A segunda parte trata do conceito de identidade do sujeito e de sua relação com a referenciação. Na terceira parte, discorremos brevemente sobre texto digital, colocando em foco a rede social Facebook, que é um espaço de escrita em nossa realidade atual, marcada pelos avanços das tecnologias digitais; na quarta parte, apresentamos nossa proposta de análise em que refletimos sobre o processo de construção dos referentes e como isso pode influenciar na construção identitária do sujeito. Na última parte, apresentamos as considerações finais, trazendo os principais resultados e contribuições deste trabalho.

Com esse propósito, guiamo-nos por um referencial teórico constituído por relevantes discussões: sobre redes sociais, Araújo e Leffa (2016); sobre texto, textualidade e análise de texto, Koch (2010, 2014, 2015 e 2017) e Antunes (2010 e 2017); sobre a linguagem on-line, Shepherd e Saliés (2013) e Barton e Lee (2015); sobre referenciação, Cavalcante (2003, 2012, 2013 e 2014); sobre linguagem e discurso, Charaudeau (2012); sobre referenciação, subjetividade e identidade do sujeito Farias Júnior (2017) e Martins (2016); sobre identidade Hall (1999) e Silva (2007); sobre cibercultura, Lévy (2010 e 2011); sobre cadeias do texto e referenciação, Roncarati (2010).

Assim, esperamos que os resultados possam contribuir para o desenvolvimento dos estudos sobre a referenciação, em especial as questões identitárias do sujeito postuladas no âmbito das Ciências Sociais. Nesta pesquisa, utilizaremos, como corpus, o texto digital em redes sociais.

\section{Evolução da linguística textual}

A referenciação faz parte do campo teórico e metodológico da Linguística Textual (LT). Por essa razão, de início, enfatizamos a transição das abordagens centradas nas estruturas gramaticais para aquelas voltadas ao discurso, mudança essa que fez com que questões relativas ao sentido do texto e à argumentação passassem a ser vistas não mais por 
meio de análises superficiais, restritas ao cotexto, à sua materialidade, mas pelo viés da comunicação/interação humana.

Em função disso, apresentamos aqui alguns pontos pertinentes dos escritos de Koch (2017) sobre os aspectos evolutivos da LT, tais como:

A dimensão pragmática traz à Linguística Textual uma mudança de paradigma importante. Os textos, segundo essa corrente teórica, não são considerados produtos prontos e acabados a serem estudados apenas pelo viés sintático e semântico, mas, pelo contrário, são componentes de uma atividade complexa, presente nas interações sociocomunicativas dos falantes. É nesse ponto que entram em cena os estudiosos da Teoria dos Atos de Fala, bem como os da Teoria da Atividade Verbal:

[...] Heinemann \& Viehweger (1991), ao fazerem uma retrospectiva da Linguística Textual, distinguem entre modelos contextuais e modelos comunicativos, mencionando, entre estes últimos, aqueles baseados na Teoria dos Atos de Fala e os que tomam por pressuposto a Teoria da Atividade Verbal. Comum a estes modelos é a busca de conexões determinadas por regras, entre textos e seu contexto comunicativo-situacional, mas tendo sempre o texto como ponto de partida dessa representação (KOCH, 2017, p. 27).

É preciso considerar também que "[...] na medida em que cabe a uma teoria de texto abordar a produção e recepção de textos que funcionam comunicativamente, ela terá de ser forçosamente pragmática, pois, de outra forma, não teria condições de existir” (p. 29).

Se antes a língua era estudada pela própria língua, ou seja, primando apenas por seu aspecto estrutural e semântico, na visão pragmática, era preciso considerar o seu aspecto funcional, isto é, a língua em uso nas diversas situações de comunicação. No entanto, outros estudiosos, mesmo considerando tais aspectos como válidos, ampliaram os estudos e passaram a focar os aspectos cognitivos da linguagem.

Neste ponto, a nova orientação para os estudos do texto, que surge na década de 1980, propugna que todo fazer (ação) é acompanhado de processos cognitivos. Nesse sentido, os processos mentais ocuparam uma posição central, e o texto passou a ser considerado como o resultado de tais processos. Dizendo de outra forma, para que o processo comunicativo seja exitoso, precisamos ativar certos conhecimentos acerca dos diversos tipos de atividade social, que se encontram armazenados na memória (KOCH, 2017).

E mais, nessa maneira de conceber o texto,

Todo e qualquer processo de compreensão pressupõe atividades do ouvinte/leitor, de modo que se caracteriza como um processo ativo e contínuo de construção - e não apenas de reconstrução -, no qual as unidades de sentido ativadas, a partir do texto, conectam-se a elementos suplementares de conhecimento extraídos de um modelo global também ativado em sua memória. (KOCH, 2017, p. 39). 
Nesse sentido, a inferenciação passou a ser a alternativa utilizada pelo ouvinte/leitor para tornar o texto condição fundamental para qualquer tipo de (re)elaboração da coerência textual em que as informações inferenciais são processadas on-line, ou seja, no ato da comunicação.

No entanto, as mudanças de perspectiva teórica na LT não cessaram. O estudo da cognição mostrou-se insuficiente para explicar o fenômeno complexo da comunicação humana. Assim, tornou-se necessário considerar os aspectos sociais e interacionistas em nexo com os aspectos cognitivos.

$\mathrm{Na}$ abordagem cognitivista clássica, havia uma separação entre exterioridade e interioridade e entre os fenômenos mentais e sociais. Sendo assim, o ambiente era apenas uma "fonte de informações para a mente individual" (KOCH, 2017, p. 41). Por essa razão, as críticas não tardaram a surgir, dando origem a outra corrente teórica: a sociocognitivointeracionista.

\footnotetext{
Dentro desta concepção, amplia-se, mais uma vez, a noção de contexto, tão cara à Linguística Textual. Se, inicialmente, quando das análises transfrásticas, o contexto era visto apenas como cotexto [...], tendo, quando da introdução pragmática, passado a abranger primeiramente a situação comunicativa e, posteriormente, o entorno sócio-histórico-cultural, representado na memória por meio de modelos cognitivos, ele passa a construir agora a própria interação e seus sujeitos: o contexto constrói-se, em grande parte, na própria interação (p. 43-44).
}

Um dos estudos da LT, que interessa de perto a este trabalho, é o da referenciação, que trouxe um novo entendimento acerca dos postulados teóricos sobre a noção de referência, a partir da visão sociocognitivo-interacionista.

\section{Fundamentos teóricos da referenciação}

Ao pensarmos na organização global de um texto, encontramos na referenciação uma das formas fundamentais para a construção do sentido. Por isso não é de causar surpresa a sua estreita ligação com os campos da semântica e da pragmática. Mas é preciso lembrar que as formas de referir hoje são o resultado de um processo evolutivo ocorrido no âmbito da LT, como fora abordado anteriormente.

Historicamente, no período compreendido entre as décadas de 1960 e 1970, os estudiosos do texto restringiam a referência às ligações cotextuais por anáfora e catáfora, dando primazia à correferencialidade $(\mathrm{KOCH}, 2017)$. Em outras palavras, o foco era o que se encontrava na superfície do texto e não no contexto. 
Os estudos linguísticos avançaram, e o caráter da língua como "espelho" da realidade, visão instrumentalista predominante nos estudos lógico-semânticos (MARCUSCHI, 2008), deu lugar à concepção sociocognitivo-interacionista, que concebe os sujeitos como atores sociais e na qual "o texto passa a ser considerado o próprio lugar da interação e os interlocutores, sujeitos ativos - dialogicamente - nele se constroem e por ele são construídos" (KOCH, 2017, p. 44). Nessa perspectiva, e tendo em vista que a referenciação é uma prática discursiva, "os referentes passam a ser concebidos como objetos de discurso elaborados, pelos interlocutores, no interior dessa atividade" (LIMA e FELTES, 2013, p. 32-33).

Nesse contexto, Koch (2017), apresentando as ideias de Isidoro Blikstein (2006) sobre referenciação, destaca

[...] que o fato de ser o referente (objeto mental, unidade cultural) extralinguístico não significa que deva ser relegado pela Linguística, pois ele está simplesmente situado atrás, ou antes, da linguagem, como um evento cognitivo, produto de nossa percepção. É na dimensão da percepçãocognição que se fabricam os referentes, os quais, embora destituídos de estatuto linguístico, vão condicionar o evento semântico $(\mathrm{KOCH}, 2017$, p. $59-60)$.

A partir desse ponto, reforça-se a ideia de que os referentes não são dados a priori, mas construídos nas práticas discursivas, também numa perspectiva sociocognitivointeracionista.

Outra questão que a autora esclarece é a mudança terminológica de referência para referenciação, que, por mais que sejam parecidas, têm certas particularidades que fazem muita diferença. Enquanto uma está presa ao cotexto, e é estável, a outra é instável, processual, e acontece por uma reelaboração da realidade, que se expressa por pistas cotextuais, mas que só se efetiva na consideração do contex to inteiro.

A esse respeito, Koch (2017) esclarece:

Nosso principal pressuposto no que diz respeito a essa questão é o da referenciação como atividade discursiva [...], que implica uma visão não referencial da língua e da linguagem. É esta, também, a posição de Mondada \& Dubois (1995), que as leva a postular uma instabilidade das relações entre as palavras e as coisas $(\mathrm{KOCH}, 2017$, p. 61).

Entre as operações básicas de referenciação, destacam-se a construção/ativação (introdução de um objeto textual no "endereço" cognitivo, locação); a reconstrução/reativação (reintrodução de um nódulo por processo referencial, mantendo o objeto-de-discurso saliente) e a desfocalização/desativação (um novo objeto de discurso é introduzido, ao passo que outro é desfocalizado) (KOCH, 2017). 
Essas estratégias envolvem, necessariamente, uma intersubjetividade. Dessa forma, quem escreve precisa delimitar o referente, torná-lo reconhecível, e quem lê deve identificar o referente, a partir das informações disponíveis no enunciado. Como observa Cavalcante (2012), a organização referencial é um aspecto central da textualização, dando continuidade e estabilidade ao texto, promovendo, assim, a coerência discursiva.

Vemos, portanto, que o processo de referenciação está diretamente relacionado à atividade de construção de "objetos de discurso" (referentes). À medida que determinado texto se desenvolve, é possível estabelecer diferentes formas de referir o mesmo objeto. Além disso, "os objetos referidos em um texto podem ser de natureza diversa: mais ou menos individualizados, mais ou menos salientes; mais ou menos concretos e até abstratos" (CAVALCANTE, 2012, p. 101).

Nesse contexto, e considerando os aspectos da referência e da acessibilidade, Cavalcante (2013, p. 133) esclarece que, "Quando paramos para considerar a intricada rede de conceitos e objetos que se (re)constroem na memória discursiva dos interlocutores, constatamos quanto ainda carece ser explicado, e reapreciado, dos mecanismos inferenciais da referenciação".

A autora reitera suas concepções a respeito das espécies de acessibilidade, explicando que:

Em primeiro lugar, salientamos que não adotamos o pressuposto insuficiente, e inadequado, de que é possível estabelecer uma relação a priori entre processos referenciais, tipos de acessibilidade e formas de designação de referentes. Em segundo, diremos que, em muitas instâncias de uso, será possível falar do acontecimento simultâneo de mais de um sistema de memória e de mais um tipo de acessibilidade, mesmo em situações não-previstas no quadro descritivo anterior (CAVALCANTE, 2013, p. 138).

Ressalta também que pode haver certa fusão entre dêiticos, introduções referenciais e anáforas, cujos efeitos podem ser surpreendentes. Para tanto, em todas essas questões que aborda, Cavalcante (2013) deixa bem claro que é imprescindível, em se tratando de referenciação, atentar para o papel importantíssimo da atividade do discurso em sua dimensão situacional, social e interacional.

Dito de outra forma, o processo de construção e reconstrução dos objetos se dá no interior do próprio discurso que, segundo Mondada e Dubois (2016), "são processos que se desenvolvem no seio das interações individuais e sociais com o mundo e com os outros [...]" (p. 22). Como mostraremos a seguir, todas essas concepções confluem para a relação entre referenciação e identidade, sobre a qual discorreremos no percurso desse trabalho. 


\title{
4 A relação entre referenciação, identidade e texto digital
}

Para tratar das representações de identidade com a referenciação em textos da mídia digital, começamos por discorrer, brevemente, sobre as concepções de identidade do sujeito. Trata-se de uma questão bastante complexa e, no nosso entender, uma vez que a identidade passa pelo viés cultural, um dos melhores caminhos para começar a compreendê-la é por meio de um estudo "inter" e "transdisciplinar", como sugere Silva (2007). A Psicologia e a Antropologia estão entre as ciências humanas que estudam a identidade do sujeito. E, em nosso caso, propomos estudá-la pelo viés linguístico-textual, a partir dos pressupostos da referenciação.

À primeira vista, como afirma Silva (2007, p. 74):

[...] parece ser fácil definir "identidade". A identidade é simplesmente aquilo que se é: "sou brasileiro", "sou negro", "sou heterossexual", "sou jovem", "sou homem". A identidade assim concebida aprece ser uma positividade ("aquilo que sou"), uma característica independente, um "fato" autônomo. Nessa perspectiva, a identidade só tem como referência a si própria: ela é autocontida e autossuficiente.

O mesmo vale para a questão da diferença, se levarmos em conta essa maneira de conceber a identidade. Todavia, considerar a identidade do sujeito como algo autônomo, "autorreferente", vai de encontro a muitas correntes teóricas, como, por exemplo, a do dialogismo bakhtiniano, retomado por Faraco (2009), que afirma ser a nossa constituição de sujeito uma soma de diversas vozes que nos atravessam, ou seja, "eu não posso ser sozinho", “eu só posso ser com o outro". Nesse sentido, a identidade jamais poderá ser um produto "solo", mas sempre social.

A esse respeito, Silva (2007) esclarece:

\begin{abstract}
Além de serem interdependentes, identidade e diferença partilham uma importante característica: elas são o resultado de atos de criação linguística. Dizer que são o resultado de atos de criação significa dizer que não são coisas que estejam simplesmente aí, à espera de serem reveladas ou descobertas, respeitadas ou toleradas. A identidade e a diferença têm que ser ativamente produzidas. Elas não são criaturas do mundo natural ou de um mundo transcendental, mas do mundo cultural e social. Somos nós que as fabricamos, no contexto de relações culturais e sociais. A identidade e a diferença são criações sociais e culturais (p. 76).
\end{abstract}

Logo, sendo a identidade uma produção sociocultural, o ideal é falar em "identidades", no plural. Como afirma Martins (2016, p. 56), ao ler Hall (1999), “o sujeito, previamente vivido como tendo uma identidade unificada e estável, está se tornando fragmentado; composto não de uma única, mas de várias identidades, algumas vezes contraditórias ou não resolvidas". 


\subsection{Identidade: ato de referir}

O ponto de interseção da referenciarão com a identidade do sujeito passa pela questão da intersubjetividade, que aqui apresentamos com o propósito de "analisar como os participantes envolvidos na construção do significado estão agindo no mundo através da linguagem e estão, deste modo, construindo a sua realidade social e a si mesmos" (MOITA LOPES, 1998, p. 305, apud MARTINS, 2016).

Quando analisamos os referentes em um texto, vemos que eles podem revelar traços identitários do sujeito-autor. Como explica Antunes (2017, p. 96, grifo nosso), “as expressões com que nos referimos às coisas do mundo são designativas, mas carregam também um peso ideológico, ou certo viés de valoração, conforme a percepção cultural de quem, em determinado contexto, recorre a elas".

Outro aspecto que podemos considerar é o fato de a referenciação constituir-se uma prática discursiva e, por conseguinte, realizar-se na enunciação. Para essa visão, converge uma das posições de Charaudeau (2012) sobre a relação do locutor consigo mesmo, sobre seu comportamento elocutivo:

O resultado é uma enunciação que tem como efeito modalizar subjetivamente a verdade do Propósito enunciado, revelando o ponto de vista interno do sujeito falante. Desse modo, o Propósito referencial é situado no universo de discurso do sujeito falante (CHARAUDEAU, 2012, p. 83, grifos do autor).

Na mesma linha, vale a pena observar o pensamento de Bakhtin (2000, p. 308, apud MARTINS, 2016), que afirma que "a língua enquanto sistema dispõe [...] de um rico arsenal de recursos linguísticos (lexicais, morfológicos e sintáticos) para expressar a posição emotivovalorativa do locutor".

Esses posicionamentos teóricos corroboram e culminam com o nosso propósito de demonstrar como a referenciação relaciona-se às questões de identidade.

\subsection{O texto digital e a rede social Facebook}

Uma vez que nossa proposta de aproximação entre referenciação e identidade desemboca no texto digital, especificamente, no Facebook, convém fazermos uma breve abordagem teórica sobre este tipo de texto.

Assim, começamos por Barton e Lee (2015), que mostram um aspecto bastante pertinente acerca do uso da língua em nossa realidade atual, marcada pela tecnologia digital e das interações ocorridas on-line: 
Para a linguística e o estudo da linguagem de maneira mais ampla, um conjunto de conceitos estáveis desenvolvidos nas últimas décadas caiu por terra. A palavra "texto" é um exemplo. Antes de tudo, não se pode mais pensar em textos como relativamente fixos e estáveis. Eles estão mais fluidos com as virtualidades mutantes das novas mídias. Além disso, estão se tornando cada vez mais multimodais e interativos. (BARTON e LEE, 2015, p. 31).

Nesse contexto, uma das redes sociais que pode ser estudada pelo viés linguísticodiscursivo é o Facebbok que

[...] apresenta uma justaposição de espaços on-line [...]. Além das atualizações de status, há um recurso de comentário que, por vezes, age como site para minifóruns de discussões [...] O Facebook é um dos melhores representantes da cultura de convergência. Os usuários podem facilmente se conectar a sites externos, por exemplo, um artigo de jornal, clicando o botão "curtir" (BARTON e LEE, 2015, p. 59).

Vale ressaltar também que Crystal (2001), no seu trabalho "Language and the Internet", foi o grande pioneiro dos estudos relacionados à língua e à Internet, ao lado de Lévy (2010), que discute sobre a mesma questão num posicionamento mais filosófico: "Cibercultura", "O que é o virtual" e também "As tecnologias da inteligência”. Em vista disso, "as opções de leitura oferecidas pela mídia eletrônica estão criando novas práticas, exigindo-nos crescente capacidade de integrar as informações de modo não linear" (RONCARATI, 2010, p. 18).

Todas essas questões, como asseveram Shepherd e Saliés (2013), contribuíram para o surgimento de uma nova área de estudos dentro da Linguística: a Linguística da Internet, que nos ajuda a melhor compreender a realidade de uso da língua nas diversas interfaces da Web.

Ao estudarmos o texto digital, o fazemos entendendo que os sujeitos realizam escolhas linguísticas para atender aos seus propósitos comunicativos, assim a palavra “(...) passa a ficar carregada ideologicamente" (MARTINS, 2016, p. 53). Esse carregamento ideológico, nas expressões referenciais, constitui um elemento subjetivo e, portanto, torna-se um fator preponderante na construção identitária.

\section{Uma proposta de análise}

Nesta parte do trabalho, mostramos dois quadros: o primeiro traz a transcrição do texto ${ }^{3}$ escolhido para a análise; o segundo traz a descrição dos referentes utilizados para a sua construção.

\footnotetext{
${ }^{3}$ Optamos por "copiar" e "colar", ao invés de fazer "Print Screen", porque este não permitiria inserir a numeração. O conteúdo do texto foi preservado na íntegra, sem edições ou correções, e a identidade do autor não revelada, por questões éticas.
} 
Quadro 1: Comentário facebookiano.

"Tenho dois príncipes [1] e Ø [2] sou perdidamente apaixonada por eles [3], mas $\varnothing$ [4] tenho medo dessas novas regras [5] que $\varnothing$ [6] querem obrigar impôr essa nova apologia do gênero [7], essas exposição de artes com senas de sexo bizarra [8], desfiles com homens nus no museu de artes modernas [9], e as crianças [10] todas em volta e a mãe [11] colocando a criança [12] pra tocar o corpo do homem [13].... Meus filhos [14] são príncipes [15] SIM e quem [16] decide como posso pode ser chamado somos nós [17] os MÃE e o PAI [18]".

Fonte: Rede social Facebook

Inserimos uma ordem numérica dos objetos de discurso (referentes), de acordo com o modelo adotado por Roncarati (2010), nos seus estudos sobre cadeias referenciais, para facilitar a retomada destes quando necessário.

Quadro 2: Seleção de referentes

\begin{tabular}{|l|l|}
\hline [1] $1^{\text {a }}$ menção: ativação referente no texto; & [9] recategorização do referente [8]; \\
[2] Ø (termo elíptico); & {$[\mathbf{1 0 ]}$ introdução de novo referente; } \\
[3] retomada do referente [1] por pronominalização; & {$[\mathbf{1 1}]$ introdução de novo referente; } \\
[4] Ø (termo elíptico); & {$[\mathbf{1 2}]$ retomada e recategorização do referente [10] por } \\
[5] introdução de novo referente; & repetição \\
[6] retomada do referente [5] por elipse [Ø]; & {$[\mathbf{1 3}$ introdução de novo referente } \\
[7] recategorização do referente [5]; & {$[\mathbf{1 4}]$ introdução de novo referente } \\
[8] introdução de novo referente; & {$[\mathbf{1 5}]$ retomada do referente [1] por repetição } \\
& {$[\mathbf{1 6}]$ e [17] pronomes-catafóricos do referente [18] } \\
\hline
\end{tabular}

Fonte: Autores do trabalho

No início desta análise, enfatizamos que "no âmbito da mediação por computador", muitas das materialidades das falas dos atores podem desvelar ideologias presentes e legitimadas pelas interações na sociedade". (ARAÚJO e LEFFA, 2016).

Nesse sentido, como o sujeito em questão é usuário do Facebook, isso, ao menos hipoteticamente, leva-nos a identificá-lo como alguém aberto à discussão, do contrário, não participaria dessa rede social, que segundo Oliveira e Paiva (2016, p. 70), caracteriza-se como um sistema aberto em que

[...] as discussões saem dos limites do $\mathrm{FB}^{5}$ e passam a ser tema de jornais, rádios e TVs e das conversas face a face. Da mesma forma, outras práticas sociais interferem nas ações de linguagem dentro do FB. Notícias sobre política, curiosidades, crimes

\footnotetext{
${ }^{4}$ Compreendemos o termo "computador" nas suas diversas vertentes: Tablets, Notebooks, Smartphones...

${ }^{5}$ Facebook.
} 
bárbaros, dentre outras, são reproduzidas no FB e geram debates e manifestação de opiniões.

O texto aqui analisado não foge a essa regra e mostra um posicionamento, uma "reação" a determinado post polêmico, algo característico do FB, que muitas vezes transforma-se em “minifóruns” de discussão (BARTON e LEE, 2015).

\subsection{Os traços identitários}

Os "objetos de discurso" que compõem a cadeia referencial no texto facebookiano em questão revelam-nos alguns traços identitários, mas apresentaremos apenas dois, por julgarmos estarem mais salientes no texto selecionado.

Assim, a leitura contextualizada, fundada não só nos aspectos endofóricos, mas também nos exofóricos, permite-nos identificar, ao menos transitoriamente, o sujeito em questão como sendo:

a) conservador - em virtude de seu apelo à continuidade das formas de vida familiar e sociais tradicionais (leitura das entrelinhas), e pela oposição às mudanças radicais que se desenham na sociedade atual (compreensão a que chagamos por meio de inferência e pala observação do conjunto de referentes elencados para comentar o Post). Isso fica evidente quando observamos os objetos de discurso entre [4] e [13] - que mostram também uma reação contrária às "questões de gênero" ("ideologia de gênero" - como tem sido rotulado): $\emptyset$ [4] tenho medo dessas novas regras [5] que Ø [6] querem obrigar impor essa nova apologia do gênero [7], essas exposição de artes com senas de sexo bizarra [8], desfiles com homens nus no museu de artes modernas [9], e as crianças [10] todas em volta e a mãe [11] colocando a criança [12] pra tocar o corpo do homem [13].

Vendo a evolução desses referentes e pensando nas razões que levaram o sujeito a selecioná-los para compor seu texto, encontraremos uma estreita ligação com o que afirma Bakhtin (2000, p. 311, apud MARTINS, 2016):

Ao escolher uma palavra ${ }^{6}$, partimos das intenções ao todo do nosso enunciado, e esse todo intencional, construído por nós, é sempre expressivo. É esse que irradia sua expressividade (ou melhor, nossa expressividade) para cada uma delas que escolhemos e que, dentro de certo acordo, inocula nessa palavra a expressividade do todo. Escolhemos a palavra de acordo com sua significação que, por si só, não é expressiva e pode ou não corresponder ao nosso objetivo expressivo em relação com as outras palavras, isto é, em relação com o todo de nosso enunciado.

\footnotetext{
${ }^{6} \mathrm{O}$ autor utilizou o termo "palavra", mas aqui o interpretamos como os referentes, expressões que assumem a forma de construções sintáticas que têm como núcleo substantivos - os sintagmas nominais.
} 
Diante dessa afirmação do autor, queremos esclarecer que o termo "conservador" que utilizamos para descrever um traço da identidade do sujeito desta pesquisa não é um rótulo e não tem caráter pejorativo, de modo que o adotamos apenas em virtude das convenções sociais e linguísticas que nos permitem assim caracterizá-lo. Além do mais, como afirma Silva (2007),

[...] a identidade não é uma essência; não é um dado ou um fato - seja da natureza, seja da cultura. A identidade não é fixa, estável, coerente, unificada, permanente. A identidade tampouco é homogênea, definitiva, acaba, idêntica, transcendental. Por outro lado, podemos dizer que a identidade é uma construção, um efeito, um processo de produção, uma relação, um ato performativo (SILVA, 2007, p. 96).

Assim sendo, o sujeito que ora se revela "conservador", mais tarde pode mudar de opinião e passar a ser configurado por outro termo, em virtude de diversos fatores (sociais, psicológicos, culturais, antropológicos etc.) que tornam a sua identidade fluida.

Sobre a produção de um "ponto de vista", como também pode ser caracterizado o texto em análise, Charaudeau (2012) explica:

- Ponto de vista do modo de ser, que especifica de que maneira o locutor tem conhecimento de um Propósito, corresponde às modalidades de "Constatação" e de "Saber/Ignorância.

- Ponto de vista de avaliação, que especifica de que maneira o sujeito julga o Propósito enunciado, corresponde às modalidades de "Opinião" e de "Apreciação".

[...] (CHARAUDEAU, 2012, p. 83).

O outro traço identitário emergente do texto fecebookiano é o seguinte:

b) sujeito mulher/mãe - traço percebido pelo emprego do adjetivo-predicativo “apaixonada" e pelos referentes [1], [14], [15] e [18]: "dois príncipes", "Meus filhos" são "príncipes", “os MÃE e o PAI". Esses nominativos, de acordo com as convenções socioculturais e linguístico-gramaticais sobre gênero (e não estereótipos de gênero), permitem-nos afirmar que fazem parte do universo discursivo-enunciativo de uma "mulhermãe”.

Para tanto, salientamos o pensamento de Silva (2007, p. 93), quando afirma que “[...] aquilo que dizemos faz parte de uma rede mais ampla de atos linguísticos que, em seu conjunto, contribui para definir ou reforçar a identidade que supostamente apenas estamos descrevendo".

Nesse sentido, ao utilizar os referentes acima destacados, o sujeito criou, mesmo que inconscientemente, uma autoimagem. Nesse aspecto, é importante lembrar que o processo de produção textual não envolve apenas fatores linguísticos, como observa Antunes (2010): 
[...] compreender um texto é uma operação que vai além de seu aparato linguístico, pois se trata de um evento comunicativo em que operam, simultaneamente, ações linguísticas, sociais e cognitivas.

[...] um segundo aspecto que deriva desse primeiro ponto é o fato de que o texto, como expressão verbal de uma atividade social de comunicação, envolve, sempre, um parceiro, um interlocutor. Não, simplesmente, pelo fato de que temos uma companhia quando falamos e, assim, não o fazemos sozinhos. Mas, sobretudo, pelo fato de que construímos nossa expressão verbal com o outro, a dois; de maneira que o texto vai tendo um fluxo conforme acontece a interação entre os atores da ação de linguagem (ANTUNES, 2010, p. 31-32).

Em termos identitários, podemos dizer, então, que o texto em estudo abre uma janela para compreendermos quem é o sujeito que comenta (o locutor), mas não podemos desconsiderar para isso o seu interlocutor imediato, o autor do post, e tantas outras vozes que estão por trás da ação comunicativa, como elementos ingredientes (direta ou indiretamente) da construção da identidade do sujeito.

Por outro lado, estudar a identidade do sujeito por intermédio da análise dos processos referenciais é uma tarefa demasiadamente complexa, pois há muitos fatores a serem considerados que, como vimos, ultrapassam a materialidade do texto. Entretanto, uma ideia surge como basilar: aquilo que singulariza um sujeito depende sempre do outro como referente.

Faraco (2009) afirma que boa parte dos teóricos tenta entender a interação como condicionada a fatores diversos, mas sem perder de vista as singularidades da subjetividade ou mesmo o inesperado nos eventos interacionistas. Para tanto, cita como exemplo o pensamento de George Mead.

[...] o social nunca é um dado homogêneo, mas sempre heterogêneo. O social contém uma multiplicidade daquilo que ele chama de "outros generalizados" (que poderíamos compreender como conjuntos de ações, representações, valores e atitudes que circulam numa determinada sociedade; ou, em outra terminologia, o conjunto dos pré-construídos históricos).

Desse modo, nenhum sujeito fica confinado nos limites de um único "outro generalizado", mas emerge de relações simultâneas ou consecutivas com vários "outros generalizados" [...] (FARACO, 2009, p. 145-146).

Voltando-nos ao processo de constituição dos referentes, lembramos que “[...] todo processo de compreensão é interativo, alimentado por um contrato de cooperação firmado entre o autor, o sujeito escrevente, e seu leitor, o sujeito interpretante. Os sujeitos e os sentidos se constituem simultaneamente nesse processo" (RONCARATI, 2010, p. 34).

Portanto, para chegarmos a construir uma ideia sobre a identidade do "sujeito escrevente" do texto em análise, além de considerarmos os postulados teóricos acerca da relação entre referenciação e construção identitária, utilizamos as categorias de expressões referencias apresentadas por Roncarati (2110). 


\section{CONSIDERAÇÕES FINAIS}

$\mathrm{Na}$ realização desse estudo, tivemos que fazer os recortes necessários para a delimitação temática, do contrário, não conseguiríamos dar conta de uma questão tão abrangente: a aproximação entre referenciação, identidade e texto digital. No entanto, esforçamo-nos para apresentar uma visão, mesmo que sintética, dessa tríplice relação. E nossas reflexões e análise qualitativa dos dados, à luz de um consistente arcabouço teórico, permitiram-nos chegar às seguintes conclusões:

1) A relação entre referenciação, identidade e texto digital é possível numa perspectiva de análise linguístico-textual e num olhar discursivo, isso porque a discursivização faz parte da construção identitária do sujeito que, como vimos, passa pelas interações socioculturais. O sujeito, até para dizer-se "singular", precisa do outro como referente. Nesse sentido, podemos dizer que não existe identidade que se construa apenas na unicidade, mas, sobretudo, na pluralidade.

2) O sujeito falante/escrevente, ao selecionar os objetos de discurso (referentes) que vão compor um texto, deixa transparecer traços de sua identidade, que é fruto das relações sociocognitivistas e interacionistas. Nesse sentido, podemos até parodiar um velho provérbio bíblico: “Mostra-me o que escreves e dir-te-ei quem és". Ou seja, a escrita revela aspectos importantes da identidade de quem escreve, como propõe Bakhtin (2000) em seus estudos sobre gênero e discurso.

3) A identidade não é fixa e imutável, de forma que o que se revela hoje pode não mais se revelar amanhã, em razão do caráter volátil e performático de sua construção.

4) Na rede social Facebook, há um recurso de comentário que, muitas vezes, configura-se como site para minifóruns de discussões, possibilitando aos estudiosos do texto uma análise da opinião do sujeito locutor sobre o mundo, e do seu ponto de vista interno, aspecto diretamente relacionado à construção identitária.

Isso posto, vale ressaltar que, se aprofundarmos a análise sobre a ponte referenciação, identidade e texto digital, poderemos encontrar outros aspectos relevantes da construção identitária do sujeito. No entanto, nossas abordagens sobre essa questão tiveram aqui um caráter demonstrativo, e como tal acreditamos que o caminho percorrido mostrou-se satisfatório. 


\section{REFERÊNCIAS}

ARAÚJO, Júlio; LEFFA, Vilson. Redes sociais e ensino de línguas: o que temos de aprender? 1.ed. São Paulo: Parábola Editorial, 2016.

ANTUNES, Irandé. Análise de textos: fundamentos e práticas. São Paulo: Parábola Editorial, 2010.

Editorial, 2017.

Textualidade: noções básicas e implicações pedagógicas. 1. ed. São Paulo: Parábola

BAKHTIN, Mikhail Mikhailovich. Os gêneros do discurso. In: Estética da Criação Verbal. 3. ed. São Paulo: Martins Fontes, 2000.

BARTON, David; LEE, Carmen. Linguagem online: textos e práticas digitais. 1. ed. São Paulo: Parábola Editorial, 2015.

BLINKSTEIN, Izidoro. Técnica de comunicação escrita. São Paulo: Ática, 2006.

CAVALCANTE, Mônica Magalhães. Os sentidos do texto. São Paulo: Contexto, 2012.

CAVALCANTE, Mônica Magalhães; LIMA, Silvana Maria Calixto (Orgs.). Referenciação: teoria e prática. São Paulo: Cortez, 2013.

CHARAUDEAU, Patrick. Linguagem e discurso: modos de organização. 2. ed. São Paulo: Contexto, 2012.

CRYSTAL, David. Language and the Internet. Cambridge University Press, 2001.

FARACO, Carlos Alberto. Linguagem e diálogo: as ideias do Círculo de Bakhtin. São Paulo: Parábola, 2009.

HALL, Stuart. A identidade cultural na pós-modernidade. 3. ed. Rio de Janeiro: DP\&A, 1999.

$\mathrm{KOCH}$, Ingedore Villaça. Introdução à linguística textual: trajetória e grandes temas. 2. ed. São Paulo: Contexto, 2017.

LÉVY, Pierre. Cibercultura. 3. ed. São Paulo: Editora 34, 2010.

LIMA, Silvana Maria Calixto; FELTES, Heloísa Pedroso de Moraes. A construção de referentes no texto/discurso: um processo de múltiplas âncoras. In: CAVALCANTE, Mônica Magalhães; LIMA, Silvana Maria Calixto (Orgs.). Referenciação: teoria e prática. São Paulo: Cortez, 2013.

MARCUSCHI, Luiz Antônio. Produção textual, análise de gêneros e compreensão. 3. ed. São Paulo: Parábola Editorial, 2008.

MARTINS, Waldiney Corrêa. A construção de uma ponte: linguagem, referenciação, subjetividade e identidade. 2016. 115f. Dissertação (Mestrado). Universidade Estadual de Ponta Grossa. Ponta Grossa, 2016. 
MOITA LOPES, Luiz Paulo da, 1998 . Discurso e identidades em de aula de L1: a construção da diferença. In: MARTINS, Waldiney Corrêa. A construção de uma ponte: linguagem, referenciação, subjetividade e identidade. 2016. 115f. Dissertação (Mestrado). Universidade Estadual de Ponta Grossa. Ponta Grossa, 2016.

MONDADA, Lorenza; DUBOIS, Danièle. Construção dos objetos de discurso e categorização: uma abordagem dos processos de referenciação. In: CAVALCANTE, Mônica Magalhães; RODRIGUES, Bernadete Biasi; CIULLA, Alena. Referenciação. São Paulo: Contexto, 2016.

OLIVEIRA, Vera Lúcia Menezes; PAIVA. Facebook: um trator na internet. In: ARAÚJO, Júlio; LEFFA, Vilson. Redes sociais e ensino de línguas: o que temos de aprender? 1. ed. São Paulo: Parábola Editorial, 2016.

RONCARATI, Cláudia. As cadeias do texto: construindo sentidos. São Paulo: Parábola Editorial, 2010.

SHEPHERD, Tânia G.; SALIÉS, Tânia G. Linguística da internet. São Paulo: Contexto, 2013.

SILVA, Tomaz Tadeu da (org.). Identidade e diferença: a perspectiva dos estudos culturais. 7. ed. Petrópolis, RJ: Vozes, 2007. 